\title{
Reversible Memory Loss in a Mouse Transgenic Model of Alzheimer's Disease
}

\author{
Linda A. Kotilinek, ${ }^{1}$ Brian Bacskai, ${ }^{2}$ Marcus Westerman, ${ }^{1}$ Takeshi Kawarabayashi, ${ }^{3}$ Linda Younkin, ${ }^{3}$ \\ Bradley T. Hyman, ${ }^{2}$ Steven Younkin, ${ }^{3}$ and Karen H. Ashe ${ }^{1}$ \\ ${ }^{1}$ Departments of Neurology and Neuroscience, University of Minnesota, Minneapolis 55455, 2Department of Neurology, \\ Massachusetts General Hospital East, Charlestown, Massachusetts 02129, and ${ }^{3}$ Department of Neuroscience, Mayo \\ Clinic, Jacksonville, Florida 32224
}

\begin{abstract}
Alzheimer's disease (AD) is a neurodegenerative condition, believed to be irreversible, characterized by inexorable deterioration of memory and intellect, with neuronal loss accompanying amyloid plaques and neurofibrillary tangles. In an amyloid precursor protein transgenic mouse model, Tg2576, little or no neuronal loss accompanies age-related memory impairment or the accumulation of $A \beta$, a $40-42$ aa polypeptide found in plaques. Recently, we have shown inverse correlations between brain $A \beta$ and memory in Tg2576 mice stratified by age (Westerman et al., 2002). Broadening the age range examined obscured this relationship, leading us to propose that small, soluble assemblies of $A \beta$ disrupt cognitive function in these mice. Here we show that memory loss can be fully reversed in
\end{abstract}

Tg2576 mice using intraperitoneally administered BAM-10, a monoclonal antibody recognizing the $N$ terminus of $A \beta$. The beneficial effect of BAM-10 was not associated with a significant $A \beta$ reduction, but instead eliminated the inverse relationship between brain $A \beta$ and memory. We postulate that BAM-10 acts by neutralizing $A \beta$ assemblies in the brain that impair cognitive function. Our results indicate that a substantial portion of memory loss in Tg2576 mice is not permanent. If these $A \beta$ assemblies contribute significantly to memory loss in $A D$, then successfully targeting them might improve memory in some AD patients.

Key words: Alzheimer's disease; transgenic; behavior; $A \beta$; monoclonal antibodies; memory
The Tg2576 transgenic mouse model of Alzheimer's disease (AD), which overexpresses a mutant form of amyloid precursor protein (APP), APP $\mathrm{K}_{\mathrm{K} 70 / 671 \mathrm{~L}}$, linked to early onset familial AD, develops amyloid plaques and progressive cognitive deficits (Hsiao et al., 1996). In these mice, $\mathrm{A} \beta$ begins to rise rapidly at $\sim 6$ months, coincident with the appearance of detergent-insoluble A $\beta$ (Kawarabayashi et al., 2001), and memory ability declines progressively thereafter (Westerman et al., 2002). Punctate, cored plaques are present in 7- to 8-month-old mice; mature, diffuse plaques appear at $\sim 12$ months of age (Kawarabayashi et al., 2001). Descriptive characterizations of the relationship between memory and $\mathrm{A} \beta$ in Tg2576 mice (Westerman et al., 2002), along with active $\mathrm{A} \beta$ immunization studies in Tg2576 and other APP transgenic mice (Janus et al., 2000; Morgan et al., 2000), have demonstrated that $\mathrm{A} \beta$ is necessary and sufficient to disrupt memory and have implicated a soluble $\mathrm{A} \beta$ assembly rather than the accumulation of $\mathrm{A} \beta$ or amyloid plaques per se.

Received April 1, 2002; revised May 10, 2002; accepted May 20, 2002.

This work was supported by National Institutes of Health Grants AG15453 (K.H.A., B.T.H., S.Y.), NS33249 (K.H.A.), MH65465 (K.H.A.), and AG08687 (B.T.H.); by a Pioneer Award from the Alzheimer's Association (B.T.H.); and by The Walter Family Foundation (B.T.H.). We gratefully acknowledge Stefanie Schrump, Deirdre Cooper-Blacketer, Jennifer Perry, Aaron Guimaraes, Jennifer Lang, Jennifer Paulson, and Nardina Nash for their expertise and dedication testing mice in the water maze. We thank Megan McLellan and Steve Kajdasz for technical assistance with immunohistological procedures and Eugene Gnida for technical help performing ELISAs.

Correspondence should be addressed to Karen H. Ashe, Department of Neurology, Mayo Mail Code 295, 420 Delaware Street Southeast, Minneapolis, MN 55455. E-mail: hsiao005@umn.edu.

T. Kawarabayashi's present address: Department of Neurology, Okayama University Graduate School of Medicine, Okayama, 700-8558 Japan.

Copyright (C) 2002 Society for Neuroscience $0270-6474 / 02 / 226331-05 \$ 15.00 / 0$
There have been no studies addressing whether the deleterious effects of $\mathrm{A} \beta$ on cognitive function are permanent. $\mathrm{Tg} 2576$ mice at 16 months of age with mature plaque deposition show no neuronal or synaptic loss (Irizarry et al., 1997), leading us to surmise that cognitive impairment in these mice might be attributable to neuronal dysfunction rather than neuronal degeneration. Based on previous studies of the relationship between $\mathrm{A} \beta$ and memory in Tg2576 mice (Westerman et al., 2002), we hypothesized that if cognitive deficits related to toxic $\mathrm{A} \beta$ assemblies occur primarily in the absence of structural damage, then passive administration of antibodies to $\mathrm{A} \beta$ might rapidly reverse learning and memory deficits by neutralizing one or more critical $\mathrm{A} \beta$ species, thereby restoring normal cognitive function. To focus our evaluation on alterations in cognitive function that occur before plaque deposition, we tested Tg2576 mice at 9-11 months after the appearance of detergent-insoluble $\mathrm{A} \beta$, but preceding the accumulation of abundant mature amyloid plaques (Kawarabayashi et al., 2001). At this age, punctate deposits are present but are rare and difficult to quantify meaningfully. Because passive immunization affects molecular targets more rapidly and selectively than active immunization, we chose passive immunization as a tool to clarify the molecular mechanism by which memory loss occurs in $\mathrm{Tg} 2576$ mice.

\section{MATERIALS AND METHODS}

Mice and behavioral testing. Forty-three female $\operatorname{Tg} 2576$ mice, positive for the HuAPP695.K670N/M671L transgene in a hybrid C57BL/6/SJL background (Hsiao et al., 1996), were longitudinally tested twice at 9-11 months of age; a total of $17 \mathrm{Tg} 2576$-positive mice (10 female, 7 male) were longitudinally tested at 2 and 8 months of age, and 10 littermates negative for the transgene ( 7 female, 3 male) were tested at 3 months of 
age, in the reference memory version of the Morris water maze (Morris, 1984), as described previously (Westerman et al., 2002).

In the longitudinal experiment involving 9- to 11-month-old mice, a baseline assessment of the cohort was obtained immediately before immunization, first in the visible-platform version of the water maze ( 3 $\mathrm{d}$, eight trials per day) followed by hidden-platform testing ( $9 \mathrm{~d}$, four trials per day). The spatial memory for the platform position was evaluated in 1 min probe trials administered at the beginning of days 4, 7, and 10 of hidden platform testing. Mice were allocated to the two treatment groups that were counterbalanced on the basis of the mean of the three baseline probe scores. All cues were changed, and the platform position was shifted to the opposite quadrant during subsequent retesting of immunized mice performed 11-12 d after the termination of the baseline water maze test. Only a hidden-platform version of the water maze test was performed. The order of testing mice from different experimental groups was random, and the experimenters were unaware of the treatment group. Eight mice that were unable to learn the visible-platform test or be led out of the pool with an escape scoop were removed from the experiment, a proportion consistent with previous studies (Westerman et al., 2002). One mouse died during baseline testing, before immunization, and another mouse died 1-2 hr after the final BAM-10 injection, reducing the final control (IgG) and treatment (BAM-10) group sizes to 17 and 16 , respectively. The latter mouse showed no signs of illness at the time of injection, making it likely that the acute death was related to a traumatic injection rather than to encephalitis.

Seventeen naive Tg2576 mice, along with 10 transgene-negative littermates, were also tested at 2 and 3 months of age, respectively, using the same protocol, except that these mice were prehandled before testing. Prehandling consisted of performing preparative maneuvers resembling procedures used during testing 8-10 times during the 2-3 weeks before actual testing. Previous cross-sectional studies of spatial reference memory during the lifetime of $\mathrm{Tg} 2576$ mice in the C57BL/6/SJL background have shown no differences between $\mathrm{Tg} 2576$ mice at $<6$ months of age and nontransgenic littermates at $<20$ months of age (Westerman et al., 2002). For this reason, we chose to compare Tg2576 mice at 9-11 months of age with younger Tg2576 mice and nontransgenic littermates. At 8 months of age, the $17 \mathrm{Tg} 2576$ mice were allocated into two treatment groups counterbalanced on the basis of mean probe scores at 2 months of age and gender, treated with BAM-10 or nonspecific $\mathrm{IgG}$, retested in the water maze beginning at 8.3 months of age, and killed at 8.7 months of age.

Antibody selection and administration. BAM-10 (Sigma, St. Louis, MO) is a mouse monoclonal antibody recognizing $\mathrm{A} \beta(1-12)$. BAM-10 was chosen on the basis of its ability to bind $\mathrm{A} \beta$ in vivo. Because not all antibodies bind to $\mathrm{A} \beta$ in its native configuration (B. Bacskai and $\mathrm{B}$. T. Hyman, personal communication), we used multiphoton microscopy, an in vivo imaging method with $\sim 1 \mu \mathrm{m}$ resolution, to evaluate the effectiveness of BAM-10 antibody in living Tg2576 mice. We purified, concentrated, and labeled BAM-10 with fluorescein, and applied 5-10 $\mu$ l of a 1 $\mathrm{mg} / \mathrm{ml}$ solution directly to the cortical surface of 25-month-old Tg2576 mice. We then visualized the fluorescence as described previously (Bacskai et al., 2001), readily imaging both senile plaques in the neuropil and amyloid angiopathy in the living mouse brain. The in vivo immunofluorescent signal colocalized with thioflavine S staining in cored plaques and in amyloid angiopathy, as well as revealing nonthioflavine $\mathrm{S}$ diffuse deposits (data not shown). Diffuse but not cored deposits were reduced by $53 \%$ after $3 \mathrm{~d}$ in BAM-10-treated mice, an effect similar to that obtained using another antibody recognizing the $\mathrm{N}$ terminus of A $\beta, 10 \mathrm{D} 6$ (Bacskai et al., 2001) (data not shown).

Antibodies were administered intraperitoneally beginning 4-5 d after the last day of baseline water maze pretesting in the longitudinal experiment involving 9- to 11-month-old mice, and $7 \mathrm{~d}$ before water maze testing in the experiment involving 8-month-old mice. One group of Tg2576 mice received BAM-10 ascites lacking sodium azide preservative; the other group if mice received $\operatorname{IgG}$ (Sigma). Animals received 0.5 mg of antibody on days 1,6 , and 12 and received $0.25 \mathrm{mg}$ of antibody on day 4. Mice were killed on the last day of behavioral testing, $5 \mathrm{~d}$ after the last dose.

Serum antibody titers. BAM-10 serum titers were measured using an adaptation of methods described previously (Schenk et al., 1999). Microtiter ELISA plates (Costar, Cambridge, MA) were coated with $1 \mu \mathrm{g}$ of aggregated A $\beta 42$ (American Peptide Company, Sunnyvale, CA) in PBS, pH 8.5, and blocked with $1 \%$ BSA (Sigma) in PBS, pH 7.4. Plates were washed with wash buffer (PBS, $0.05 \%$ Tween 20), and threefold serial dilutions (1:50 to $1: 1350)$ of mouse serum in PBS, $1 \%$ BSA, $0.05 \%$ Tween 20 , and $0.02 \%$ sodium azide were incubated overnight at $4^{\circ} \mathrm{C}$. Plates were
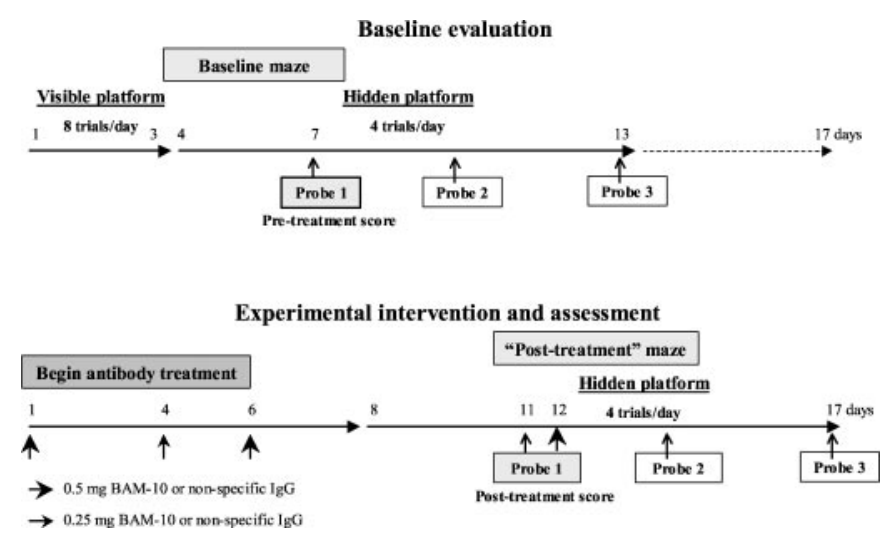

Figure 1. Longitudinal experimental design using Tg2576 mice to determine whether memory loss, once present, can be restored. Spatial reference memory was measured, using the Morris water maze (Morris, 1984), immediately before and after intraperitoneal administration of BAM-10, a monoclonal antibody recognizing the $N$ terminus of $\mathrm{A} \beta$.

washed and incubated for $1 \mathrm{hr}$ at room temperature in a 1:10,000 dilution of sheep anti-mouse HRP conjugate (Jackson ImmunoResearch, West Grove, PA) in PBS, $0.05 \%$ Tween, and $0.1 \%$ BSA. Plates were washed and developed with 3,3'5,5' tetramethylbenzidine (1-Step Slow TMB; Pierce, Rockford, IL). The reaction was stopped with an equal volume of $1 \mathrm{M} \mathrm{H}_{2} \mathrm{SO}_{4}$, and plates were read at $450 \mathrm{~nm}$. Optical densities (ODs) of equivalently diluted normal mouse serum were subtracted from test sera to obtain the net OD. The antibody titer was defined as the dilution of serum yielding a net OD that was $50 \%$ of the maximal signal for that specimen.

A $\beta$ measurements. A $\beta$ was measured by ELISA using the 3160 capture antibody described previously (Kawarabayashi et al., 2001).

\section{RESULTS}

\section{BAM-10 restores spatial learning and memory}

We measured spatial reference memory, using the Morris water maze (Morris, 1984), immediately before and after treatment with BAM-10 (Fig. 1). Training trials were delivered in blocks of four trials per day, and probe trials were performed on the mornings after the 12th, 24th, and 36th training trials. When memory impairment in Tg2576 mice first emerges at 9-11 months of age, it can be overcome with extensive training, making Tg2576 mice appear to be comparable with nontransgenic littermates at the end of training (Westerman et al., 2002). The slower rate of learning of $\mathrm{Tg} 2576$ mice at this particular age is easily detectable at the beginning of training, in the earlier probe scores (Westerman et al., 2002). The first probe scores were therefore used to assess treatment effects in this study.

Animals were assigned to BAM-10 or IgG groups after the baseline maze, counterbalancing for probe scores. The percentage of time spent by mice in the target quadrant during the baseline test in the BAM-10 and IgG groups was not significantly different. Mice received three injections of either $0.5 \mathrm{mg}$ of BAM-10 or nonspecific mouse IgG (days 1,6 , and 12 of the experiment) with a booster of $0.25 \mathrm{mg}$ on day 4 . BAM-10 serum titers, measured using an adaptation of methods described previously (Schenk et al., 1999), ranged from 1:100 to 1:1100 at $5 \mathrm{~d}$ after the last dose. Performance in the water maze was reassessed beginning on day 8 . The two groups showed significant differences in changes in performance between baseline and posttreatment tests $[p=0.03$ by $t$ test or by two-way (treatment-by-test session) ANOVA with repeated measures], indicating a significant effect of treatment with BAM-10 (Fig. 2a).

Because not all mice deteriorate at the same rate, a minority of 

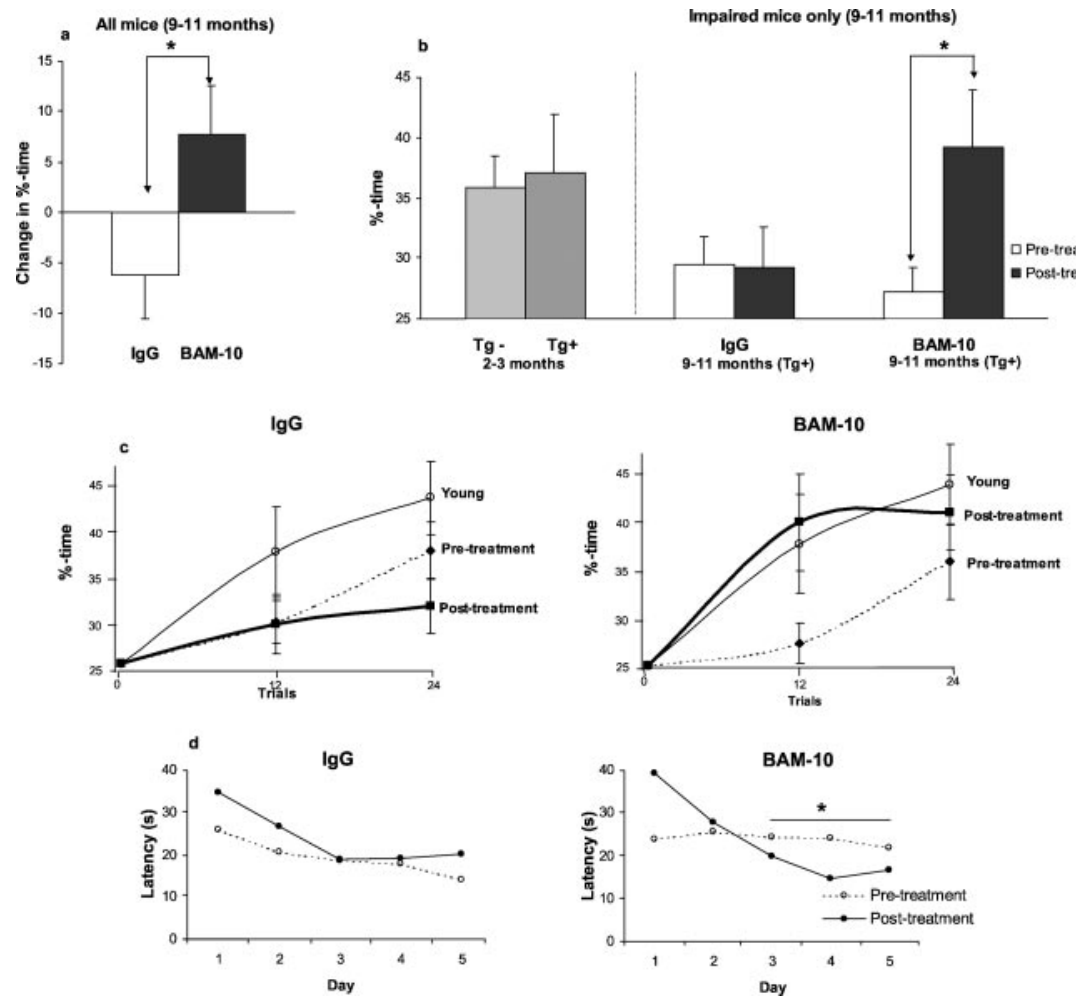

Figure 2. Spatial reference learning and memory in 9to 11-month-old $\mathrm{Tg} 2576$ mice before and after treatment with BAM-10 antibody. The change in retention of spatial memory occurring as a result of receiving BAM-10 or IgG antibodies intraperitoneally was measured by subtracting baseline scores from post-treatment scores to obtain the change in percentage of time spent in the target quadrant (Change in \%-time). a, Mice 9-11 months of age receiving BAM-10 antibody showed significantly greater improvement than mice receiving nonspecific IgG ( ${ }^{*} p=0.03$ by $t$ test; IgG, $n=17$; BAM-10, $n=16) . b$, In mice that were impaired at baseline ( $<40 \%$ of the time spent in the target quadrant), those receiving BAM-10 antibody also showed significantly greater improvement than those receiving nonspecific IgG ( ${ }^{*} p=0.04$ by two-way ANOVA with repeated measures; IgG, $n=13$; BAM-10, $n=14$ ). Posttreatment performance of impaired mice receiving BAM-10 antibody was significantly higher than baseline performance $\left({ }^{*} p=0.01\right.$ by paired $t$ test) and was similar to that of 2-month-old $\operatorname{Tg} 2576$ mice $(n=17)$ and 3-month-old nontransgenic littermates $(n=10) . c$, BAM-10, but not nonspecific IgG, restored the retention learning curve of 9- to 11-month-old $\operatorname{Tg} 2576$ mice to resemble that of 2-month-old (Young) Tg2576 mice. $d$, Acquisition of spatial reference memory improved in impaired mice receiving BAM-10 antibody, with significantly reduced mean escape latencies on days $3-5$ ( $*$ 0.04 by paired $t$ test), but not in mice receiving nonspecific IgG. There was a significant treatment-by-training session (baseline vs post-treatment) interaction ( $p=$ 0.03 by two-way ANOVA with repeated measures).
9- to 11-month-old mice showed superior performance $(>40 \%$ of time in the target quadrant) comparable with that of the top third of nontransgenic mice. We subsequently segregated the mice on the basis of baseline scores into impaired $(<40 \%$ of time in the target quadrant) and superior $(>40 \%$ of time in the target quadrant) groups. To address the question of whether BAM-10 reversed deficits, we compared the magnitude of the change between baseline and post-treatment scores in impaired mice only. There was a significant treatment-by-test session (baseline vs post-treatment) interaction in impaired mice ( $p=0.04$ by two-way ANOVA with repeated measures) (Fig. 2b). Post-treatment scores in impaired mice receiving IgG showed essentially no change relative to baseline scores. In contrast, impaired mice receiving BAM-10 demonstrated significantly improved scores ( $p=0.01$ by paired $t$ test) (Fig. $2 b)$. Remarkably, post-treatment memory ability in BAM-10treated mice was similar to that of nontransgenic mice tested at 3 months or transgenic mice tested at 2 months, before the onset of memory loss (Fig. 2b), indicating that the memory deficits in 9- to 11-month-old Tg2576 mice were reversed and memory was fully restored with BAM-10. These results are supported by comparing the learning curves of retention for BAM-10 and nonspecific IgG treatments in Tg2576 mice (Fig. $2 c$ ). BAM-10 restored the learning curve in 9- to 11-month-old mice to resemble that of 2-month-old $\mathrm{Tg} 2576$ mice.

The restorative effects of BAM-10 were also evident when acquisition of spatial reference information was examined in impaired mice. We compared mean escape latencies on days 3-5, because differences in the performance of $\mathrm{Tg} 2576$ mice at this age were most pronounced during this phase of training, consistent with the maximal sensitivity of the first probe trial on day 4 . There was a significant treatment-by-training session (baseline vs post-treatment) interaction for mean escape latencies $(p=0.03$ by two-way ANOVA with repeated measures). Mean escape latencies measured before and after $\operatorname{IgG}$ administration showed no significant differences [mean difference, $2.5 \mathrm{sec}$; $95 \%$ confidence interval $(\mathrm{CI}),-2.8$ to $7.8 \mathrm{sec} ; p=0.32$ by paired $t$ test] (Fig. $2 d)$. In contrast, mean escape latencies after BAM-10 treatment improved significantly (mean difference, $-6.3 \mathrm{sec} ; 95 \% \mathrm{CI},-0.3$ to $-12.2 \sec ; p=0.04$ by paired $t$ test) (Fig. $2 d$ ). We also observed longer escape latencies on day 1 of the post-treatment test in both groups of mice, suggesting a retest effect in which mice exhibited retention of spatial information from the baseline water maze test. The retest effect rapidly extinguished with retraining in the BAM-10-treated mice but not in the IgG-treated mice. The beneficial effects of BAM-10 were apparent within $11 \mathrm{~d}$ of the first antibody dose, the smallest time interval we could measure in this study, given the $8 \mathrm{~d}$ elapsing between the first dose and the commencement of retesting in the water maze and the $3 \mathrm{~d}$ training interval until the first probe trial.

\section{No significant changes were observed in $\mathbf{A} \boldsymbol{\beta}$ levels}

After behavioral testing, the brains of 19 IgG-treated mice and 18 BAM-10-treated mice were sequentially extracted first in Trisbuffered saline (TBS), then in $2 \%$ SDS, and finally in $70 \%$ formic acid (Kawarabayashi et al., 2001). A $\beta 40$ and $A \beta 42$ were then analyzed in each fraction by sandwich ELISA. This analysis showed that the improved performance in mice treated with BAM-10 was not associated with any significant reduction in total $\mathrm{A} \beta$ or in $\mathrm{A} \beta 40$ or $\mathrm{A} \beta 42$ in any of the fractions analyzed (Fig. $3 a$ ). Although BAM-10 was selected on the basis of its ability to bind to and result in the disaggregation of diffuse $\mathrm{A} \beta$ deposits in $\mathrm{Tg} 2576$ mice when very high concentrations were applied directly to the brain, it is noteworthy that a similar effect on lowering $\mathrm{A} \beta$ in the brain was not apparent in mice receiving BAM-10 intraperitoneally. 

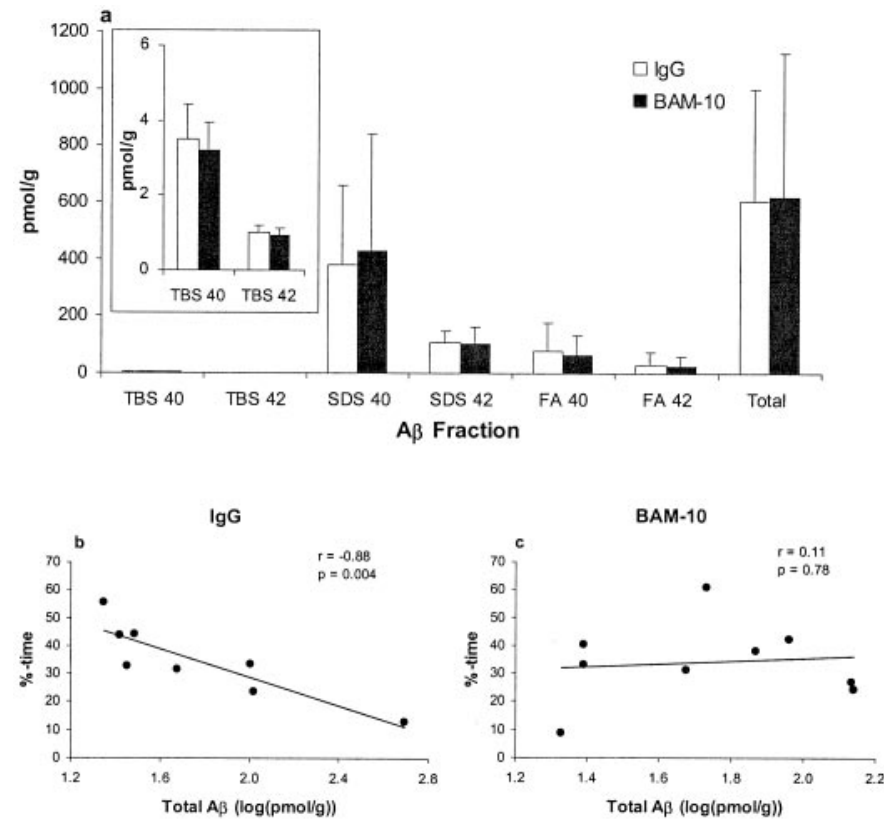

Figure 3. $\mathrm{A} \beta$ levels in $\mathrm{Tg} 2576$ mice treated with BAM-10 or nonspecific IgG antibody. Total $\mathrm{A} \beta$ is the sum of $\mathrm{A} \beta 40$ and $\mathrm{A} \beta 42$ in TBS, $2 \%$ SDS, and formic acid (FA) soluble fractions measured as described previously (Kawarabayashi et al., 2001). $a$, Treatment of mice with BAM-10 was not associated with a significant reduction in total $A \beta$ or in $A \beta 40$ or $A \beta 42$ in any of the fractions analyzed ( $p$ values ranged from 0.2 to 0.9 ). Measurements represent means \pm SDs. Brain $\mathrm{A} \beta$ levels were correlated with memory in 8.7-month-old Tg2576 mice treated with BAM-10 or nonspecific IgG antibody. $b$, There was a significant inverse correlation between total $\mathrm{A} \beta$ and probe scores in control mice treated with nonspecific IgG. $c$, Treatment with BAM-10 eliminated the correlation between total $\mathrm{A} \beta$ and probe scores.

\section{BAM-10 eliminates the inverse relationship between $A \beta$ and memory}

We have demonstrated previously that there was no obvious relationship between $\mathrm{A} \beta$ and memory in $\mathrm{Tg} 2576$ mice unless the mice were stratified by age, whereupon significant inverse correlations emerged (Westerman et al., 2002). Because $\mathrm{A} \beta$ rises very rapidly between 8 and 12 months of age (Kawarabayashi et al., 2001), tight stratification by age (in days) is necessary to obtain significant correlations between $\mathrm{A} \beta$ and memory during this time. To assess the effect of BAM-10 on the relationship between $\mathrm{A} \beta$ and memory in $\operatorname{Tg} 2576$ mice, we measured brain $\mathrm{A} \beta$ and posttreatment spatial reference memory in a second set of mice all exactly 8.7 months of age (all born within $1 \mathrm{~d}$ ), treated with either BAM-10 or nonspecific IgG according to the same schedule as mice in the previously described longitudinal experiment using 9to 11-month-old mice. As in the previous experiment, treatment with BAM-10 significantly improved memory but had no significant effect on total $A \beta$ or on $A \beta 40$ or $A \beta 42$ in any of the three fractions (data not shown). Analysis of the first probe scores showed a significant negative correlation $(r=-0.88 ; p=0.004$ by regression ANOVA) between total $\mathrm{A} \beta$ and memory in eight mice treated with nonspecific IgG (Fig. $3 b$ ). A similar negative correlation was observed in these mice for both $\mathrm{A} \beta 40$ and $\mathrm{A} \beta 42$ in each of the three fractions analyzed, with $r$ values ranging from -0.70 to -0.87 and $p$ values ranging from 0.005 to 0.05 . Because the improved spatial learning and memory in mice treated with BAM-10 was not associated with a significant reduction in $\mathrm{A} \beta$, the negative correlation between $\mathrm{A} \beta$ and probe scores was eliminated

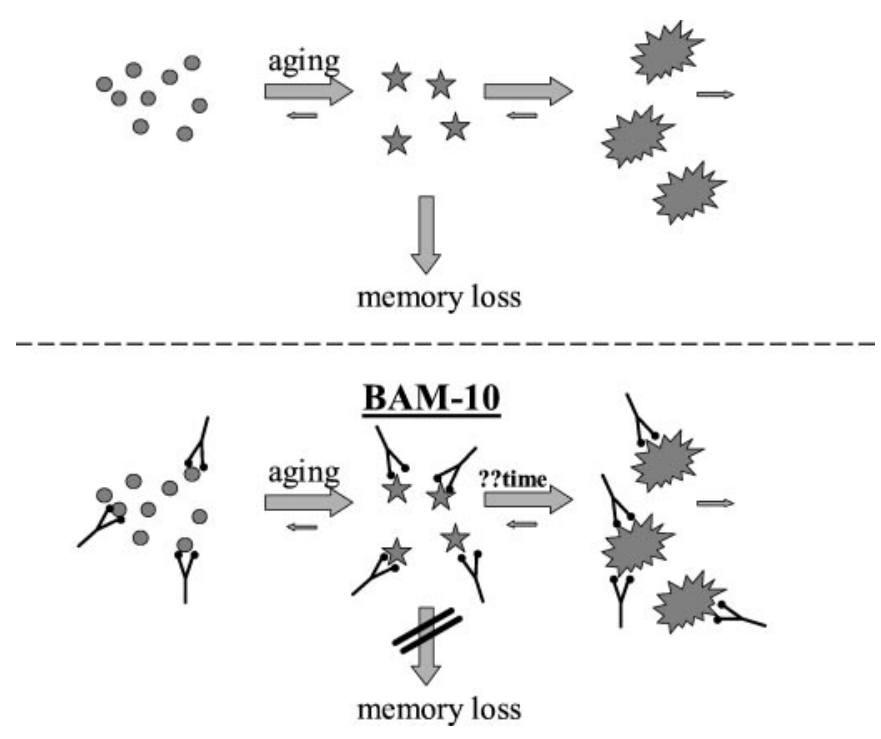

Figure 4. BAM-10 neutralizes the cognitively disruptive activity of small A $\beta$ assemblies in the brain. Top, Memory loss in Tg2576 mice appears to be caused by small A $\beta$ assemblies (stars) (Westerman et al., 2002) formed during the conversion of $\mathrm{A} \beta$ monomers (circles) to amyloid deposits (starbursts). Aging refers to the event or series of events occurring as animals age leading to the initial aggregation of monomeric $\mathrm{A} \beta$. Little is known about what comprises these events. Bottom, BAM-10 penetrates into the brain, where it may bind to these small $\mathrm{A} \beta$ assemblies, neutralize their deleterious effects on cognitive function, and rapidly restore memory in $\mathrm{Tg} 2576$ mice. With prolonged treatment, a reduction in amyloid deposits may occur.

by BAM-10 treatment. As shown in Figure $3 c$, there was no significant correlation between $\mathrm{A} \beta$ and probe scores in nine mice treated with BAM-10 $(r=0.11 ; p=0.78$ by regression ANOVA $)$.

Although serum BAM-10 titers showed a 10 -fold range in levels, there was no correlation between peripheral BAM-10 titers and probe scores $\left(r^{2}=0.0002\right)$, indicating that the effect of BAM-10 on memory did not depend on blood levels of the antibody. These results suggest that BAM-10 enters the CNS and rapidly neutralizes the deleterious effects of small $\mathrm{A} \beta$ assemblies that interfere with cognitive function, thus restoring normal memory in $\mathrm{Tg} 2576$ mice.

\section{DISCUSSION}

Active immunization with $\mathrm{A} \beta$ was first shown to prevent amyloid deposition (Schenk et al., 1999) and was subsequently shown to prevent cognitive decline (Janus et al., 2000; Morgan et al., 2000) in two APP transgenic models of AD. Passive administration of $\mathrm{A} \beta$ antibodies intraperitoneally (Bard et al., 2000) as well as direct application of $\mathrm{A} \beta$ antibodies to the brain (Bacskai et al., 2001 ) resulted in a reduction of amyloid burden and $A \beta$ levels and a rapid dispersal of deposits. None of these studies addressed the question of whether cognitive deficits, once present, could be restored to normal. Our results show that $\mathrm{A} \beta$ antibodies can indeed reverse behavioral deficits in a relatively short period of time. Although the IgG-treated mice performed nearly as well as BAM-10-treated mice after extensive training (data not shown), this does not diminish the observation that learning and memory occurred significantly more slowly in the IgG-treated group.

We postulate that BAM-10, like other $\mathrm{A} \beta$ antibodies (Bard et al., 2000), enters the CNS and acts by neutralizing soluble $A \beta$ assemblies disrupting cognitive function. These results support the model we developed to explain the relationship between $\mathrm{A} \beta$ 
and memory in Tg2576 mice (Westerman et al., 2002) (Fig. 4). Whether the same reversal effect would occur in older Tg2576 mice, where the presumably small amounts of BAM-10 entering the brain would bind to abundant amyloid deposits and therefore might be less available to neutralize soluble $\mathrm{A} \beta$ assemblies, is unknown. The direct interaction of BAM-10 with $\mathrm{A} \beta$ in the brain is in contrast to the mechanism of action proposed for $\mathrm{m} 266$ which, when chronically administered, lowers brain $\mathrm{A} \beta$ levels (DeMattos et al., 2001). It has been suggested that m266 exerts its action primarily from outside of the CNS, by creating a peripheral $\mathrm{A} \beta$ sink that draws $\mathrm{A} \beta$ out of the brain by mass action (DeMattos et al., 2001). We cannot exclude the possibility that BAM-10 exerts a similar indirect effect on brain $\mathrm{A} \beta$ in $\mathrm{Tg} 2576$ mice. Arguing against this mechanism, however, are the insignificant changes in brain $\mathrm{A} \beta$ after BAM-10 administration that are in contrast to the dramatic improvement in memory and the absence of any correlation between serum antibody titers and memory. Whether m266 and BAM-10 operate at distinct sites is an important question to resolve, because whether $\mathrm{A} \beta$ antibodies act within or outside of the CNS has important implications for potential inflammatory reactions in human $\mathrm{A} \beta$ immunization studies.

The rapid and full restoration of memory suggests that most if not all of the memory impairment in $\operatorname{Tg} 2576$ mice at this age occurs by this mechanism, and implies that little if any structural damage is associated with this type of $\mathrm{A} \beta$-mediated brain dysfunction. The possibility that memory loss in humans might be reversed depends on the extent to which the same molecular mechanism that disrupts cognitive function in $\mathrm{Tg} 2576$ mice also exists in AD (Klein et al., 2001). Tg2576 mice may represent a model in which memory loss in certain early stages of AD can be studied. If $\mathrm{A} \beta$ species that functionally impair normal cognition contribute significantly to Alzheimer's dementia, especially in the early stages, then successfully targeting these species might improve or restore cognitive function.

Note added in proof. Rapid reversal of memory loss has also been shown in PDAPP mice receiving passively administered m266 A $\beta$ antibodies (Dodart et al., 2002), which, together with the findings reported here, suggests a common mechanism for memory loss in transgenic APP mice.

\section{REFERENCES}

Bacskai BJ, Kajdasz ST, Christie RH, Carter C, Games D, Seubert P, Schenk D, Hyman BT (2001) Imaging of amyloid- $\beta$ deposits in brains of living mice permits direct observation of clearance of plaques with immunotherapy. Nat Med 7:369-372.

Bard F, Cannon C, Barbour R, Burke RL, Games D, Grajeda H, Guido T, Hu K, Huang J, Johnson-Wood K, Khan K, Kholodenko D, Lee M, Lieberburg I, Motter R, Nguyen M, Soriano F, Vasquez N, Weiss K, Welch B, et al (2000) Peripherally administered antibodies against amyloid $\beta$-peptide enter the central nervous system and reduce pathology in a mouse model of Alzheimer disease. Nat Med 6:916-919.

DeMattos RB, Bales KR, Cummins DJ, Dodart JC, Paul SM, Holtzman DM (2001) Peripheral anti-A $\beta$ antibody alters CNS and plasma $A \beta$ clearance and decreases brain $A \beta$ burden in a mouse model of Alzheimer's disease. Proc Natl Acad Sci USA 98:8850-8855.

Dodart JC, Bales KR, Gannon KS, Greene SJ, DeMattos RB, Mathis C, DeLong CA, Wu S, Wu X, Holtzman DM, Paul SM (2002) Immunization reverses memory deficits without reducing brain Abeta burden in Alzehimer's disease model, Nat Neurosci 5:452-457.

Hsiao K, Chapman P, Nilsen S, Eckman C, Harigaya Y, Younkin S, Yang F, Cole G (1996) Correlative memory deficits, $A \beta$ elevation, and amyloid plaques in transgenic mice. Science 274:99-102.

Irizarry MC, McNamara M, Fedorchak K, Hsiao K, Hyman BT (1997) APPSw transgenic mice develop age-related $\mathrm{A} \beta$ deposits and neuropi abnormalities, but no neuronal loss in CA1. J Neuropathol Exp Neurol 56:965-973.

Janus C, Pearson J, McLaurin J, Mathews PM, Jiang Y, Schmidt SD, Chishti MA, Horne P, Heslin D, French J, Mount HT, Nixon RA Mercken M, Bergeron C, Fraser PE, St George-Hyslop P, Westaway D (2000) A $\beta$ peptide immunization reduces behavioural impairment and plaques in a model of Alzheimer's disease. Nature 408:979-982.

Kawarabayashi T, Younkin LH, Saido TC, Shoji M, Ashe KH, Younkin SG (2001) Age-dependent changes in brain, CSF, and plasma amyloid $\beta$ protein in the Tg2576 transgenic mouse model of Alzheimer's disease. J Neurosci 21:372-381.

Klein WL, Krafft GA, Finch CE (2001) Targeting small A $\beta$ oligomers: the solution to an Alzheimer's disease conundrum? Trends Neurosci 24:219-224.

Morgan D, Diamond DM, Gottschall PE, Ugen KE, Dickey C, Hardy J, Duff K, Jantzen P, DiCarlo G, Wilcock D, Connor K, Hatcher J, Hope C, Gordon M, Arendash GW (2000) A $\beta$ peptide vaccination prevents memory loss in an animal model of Alzheimer's disease. Nature 408:982-985.

Morris R (1984) Developments of a water-maze procedure for studying spatial learning in the rat. J Neurosci Methods 11:47-60.

Schenk D, Barbour R, Dunn W, Gordon G, Grajeda H, Guido T, Hu K, Huang J, Johnson-Wood K, Khan K, Kholodenko D, Lee M, Liao Z, Lieberburg I, Motter R, Mutter L, Soriano F, Shopp G, Vasquez N, Vandevert $C$, et al (1999) Immunization with amyloid- $\beta$ attenuates Alzheimer-disease-like pathology in the PDAPP mouse. Nature 400:173-177.

Westerman M, Cooper-Blacketer D, Mariash A, Kotilinek L, Kawarabayashi T, Younkin LH, Carlson G, Younkin SG, Ashe KH (2002) The relationship between $\mathrm{A} \beta$ and memory in the Tg2576 mouse model of Alzheimer's disease. J Neurosci 22:1858-1867. 